\title{
Stomatal Closure Sets in Motion Long-Term Strategies of Plant Defense Against Microbial Pathogens
}

\author{
Shashibhushan Gahir ${ }^{\dagger}$, Pulimamidi Bharath ${ }^{\dagger}$ and Agepati S. Raghavendra* \\ Department of Plant Sciences, School of Life Sciences, University of Hyderabad, Hyderabad, India
}

Keywords: guard cells, innate immunity, peroxisomes, photorespiration, secondary messengers, transpiration

\section{INTRODUCTION}

Stomata are the main gateways for the entry of microbial pathogens into leaves (Melotto et al., 2008). However, some try to use hydathodes (Hugouvieux et al., 1998) or breach the cuticle (Grimmer et al., 2012). Stomatal closure, therefore, is an effective measure to restrict pathogen entry and provide the plants an innate immunity (Melotto et al., 2008, 2017; Sawinski et al., 2013; Bharath et al., 2021). Stomata open when the guard cells are turgid and close when guard cells are flaccid (Willmer and Fricker, 1996). Whenever plants are exposed to stress, the guard cells sense and respond by a series of steps that include the production of ROS and NO followed by a rise in $\mathrm{Ca}^{2+}$

Edited by:

Juan Dong,

The State University of New Jersey,

United States and the modulation of ion channels. These events promote the efflux of cations and anions from guard cells. As a result, guard cells lose turgor leading to stomatal closure (Arnaud and Hwang, 2015; Agurla et al., 2018; Saito and Uozumi, 2019; Hsu et al., 2021).

The reopening of stomata is usually slower than the closure, ensuring that the leaves conserve water for an extended period. For example, abscisic acid (ABA)-induced stomatal closure in the epidermis took about $30 \mathrm{~min}$ (and in leaf $3 \mathrm{~h}$ ). In contrast, recovery took 1-6 days, implying shortterm and long-term effects on stomata (Liang and Zhang, 1999). Recently, we pointed out that the stomatal closure by ABA was an essential component of plant adaptation to stress factors (Bharath et al., 2021). This article proposes that the initial stomatal closure response triggers many defensive strategies to fight the pathogens. We describe the follow-up of events limiting pathogen spread and emphasize stomata's role in ensuring plants' long-term adaptation against microbes.

tThese authors have contributed equally to this work

Specialty section:

This article was submitted to

Plant Cell Biology,

a section of the journal

Frontiers in Plant Science

Received: 20 August 2021 Accepted: 01 September 2021 Published: 27 September 2021

Citation:

Gahir S, Bharath P and Raghavendra AS (2021) Stomatal Closure Sets in Motion Long-Term Strategies of Plant Defense Against

\section{Stomatal Closure: An Immediate Barrier of Microbial Entry}

Stomatal closure was a typical response against microbial attack (Arnaud and Hwang, 2015; Melotto et al., 2017; Agurla et al., 2018). The process of stomatal closure is initiated by sensing the abiotic (e.g., drought, chilling, and UV-B) or biotic stress (pathogens and insects) components (Agurla et al., 2018). Most microbial pathogens produce pathogen-or microbe-or damage-associated molecular patterns (PAMPs/MAMPs/DAMPs), perceived by pattern recognition receptors (PRRs) present on the plant plasma membrane. Upon perception, plants activate a defense response called pattern-triggered immunity (PTI). When pathogens attempt to overcome PTI, plants trigger effector-triggered immunity (Cui et al., 2015; Nguyen et al., 2021). Bacterial elicitors that trigger stomatal closure include flagellin22 (flg22), lipopolysaccharide, and other elicitor peptides, such as, elf26 (Melotto et al., 2008, 2017; Arnaud and Hwang, 2015). Fungal elicitors, such as, chitin oligosaccharide and chitosan, also induced defense responses in plants (Ye et al., 2020).

Guard cells perceive hormones (e.g., ABA) or elicitors (flg22) by their respective receptors. Upon binding to $\mathrm{ABA}$ or flg22, the receptor kinases (e.g., open stomata 1 or botrytis-induced kinase 1) activate $\mathrm{RbohD} / \mathrm{F}$ and stimulate reactive oxygen species (ROS) production during stomatal closure. However, the role of RBOHD in resistance against pathogens, particularly during pre-invasive stage is not clear. The elevated ROS, in turn, trigger a rise in nitric oxide $(\mathrm{NO})$ and $\mathrm{Ca}^{2+}$. The interaction 
of these secondary messengers ( $\left.\mathrm{ROS} / \mathrm{NO} / \mathrm{Ca}^{2+}\right)$ regulates the downstream components in guard cells. Both $\mathrm{NO}$ and $\mathrm{Ca}^{2+}$ (via $\mathrm{Ca}^{2+}$-dependent protein kinases) promote the ion efflux by activating $\mathrm{K}^{+}$out, SLAC1, and SLAH3 channels and at the same time inhibit the K-influx channel (Arnaud and Hwang, 2015; Agurla et al., 2018; Kohli et al., 2019; Sun et al., 2019). Similarly, ROS and $\mathrm{Ca}^{2+}$ activate $\mathrm{Ca}^{2+}$ influx and increase cytosolic $\mathrm{Ca}^{2+}$ levels (Klüsener et al., 2002). The elevated ROS, NO, $\mathrm{Ca}^{2+}$ and $\mathrm{H}_{2} \mathrm{~S}$ provide an extended pathogen resistance (Gahir et al., 2020; Liu and Xue, 2021). Cytosolic $\mathrm{pH}$ is another secondary messenger that preceded the production of ROS and NO in guard cells, but the exact mechanism is ambiguous (Gonugunta et al., 2009; Bharath et al., 2021). It is necessary to study if such changes in pHcyt can modulate the pathogen resistance as well.

\section{Stomatal Closure Associated With the Modulation of Plant Hormones}

Stomatal closure during drought or microbial infection was associated with an increase in plant hormones. Salicylic acid (SA), ABA, methyl jasmonate (MJ), and ethylene (ET) accumulate when microbes attack plants. The concerted action of these hormones causes stomatal closure and induces systemic resistance (Gimenez-Ibanez et al., 2016; van Butselaar and Van den Ackerveken, 2020; Bharath et al., 2021). The modulated hormonal status provides long-term protection to plants against biotic and abiotic stress (Described below).

\section{DISCUSSION}

\section{Closure Triggers a Network of Long-Term Events to Ensure the Protection}

Stomatal closure in response to microbial infection is an immediate physical measure to prevent microbial entry. However, such closure has long-term effects, such as, a marked decrease in the intercellular $\mathrm{CO}_{2}$ of leaves, a reduction in photosynthetic carbon assimilation, and an elevation in photo respiratory activity. The reduction in transpiration can cause mineral deficiency in leaves. We describe below the consequences of these events and a few associated components.

\section{Decrease in Photosynthesis and Increase in Photorespiration and Peroxisomal Population}

When stomata close, the intercellular $\mathrm{CO}_{2}$ is lowered, and transpiration decreased, raising the leaf temperature. Both these factors enhance photorespiration. The increase in photorespiration occurred under conditions of biotic (microbial infection) or abiotic stress (drought) (Lal et al., 1996; Pascual et al., 2010; Voss et al., 2013; Vo et al., 2021). Even fluctuations in transpiration triggered an increase in photorespiration (Furutani et al., 2020). The enhanced photorespiration and the associated rise in $\mathrm{H}_{2} \mathrm{O}_{2}$ could confer disease resistance (Taler et al., 2004; Kubo, 2013; Sørhagen et al., 2013). Further, glycolate, glyoxylate, and glycine, being pathway intermediates, accumulate. Glycolate and glyoxylate are toxic to living cells and can double up as antimicrobial compounds. Glycine is the precursor of glutathione, an essential anti-oxidant in plant cells. Photo respiratory enzymes/metabolites mediated the plant defense during tomato-Pseudomonas syringae interactions (Ahammed et al., 2018). Thus, photo respiratory metabolism could help to resist pathogens.

The enhanced photorespiration was often associated with an increase in the peroxisomal population in leaf cells (Chen et al., 2016). Peroxisomal ROS could protect against plant pathogens (Sørhagen et al., 2013). Besides ROS, other components of peroxisomes, namely $\mathrm{NO}, \mathrm{Ca}^{2+}$, and polyamines (PA), upregulated the genes involved in SA signaling and PA catabolism, reinforcing plant defense responses (Chen et al., 2016; Wang et al., 2019).

\section{Stomatal Closure Lowers Leaf Sugars}

Stomatal closure, whether due to pathogen attack or drought, causes reduced $\mathrm{CO}_{2}$ assimilation and decreased carbon partitioning into sucrose and starch (Wang et al., 2016; Haider et al., 2017). The pathogens required sugars for growth and infection (Solomon et al., 2003; Scharte et al., 2005; Chang et al., 2017). If sufficient sucrose is not available, the extent of proliferation would be restricted (Huai et al., 2020). Therefore, the deficiency in sugar availability lead to decreased fungal growth (Bezrutczyk et al., 2018).

\section{Reduced Transpiration Creates Mineral Deficiency}

Transpiration is a prerequisite for long-distance transport of minerals (Ruiz and Romero, 2002). A deficiency of minerals would occur when stomata are closed. There was a positive relationship between the transpiration rate and mineral content of sunflower (Helianthus annuus) and maize leaves (Tanner and Beevers, 2001; Shrestha et al., 2021). Since microbial spread and multiplication within leaves depend on macronutrients/micronutrients, the mineral deficiency could affect microbial growth and enhance pathogen tolerance (Fernández-Escobar, 2019). The N-status of leaves modulated defense-related hormones, NO content, and then genes (Sun et al., 2020). The deficiency of $\mathrm{N}$ increased the levels of phenolics and restricted the spread of powdery mildew (Bavaresco and Eibach, 1987). A similar situation under $\mathrm{K}^{+}$-deficiency was reported with leaf spot, caused by Helminthosporium cynodontis (Richardson and Croughan, 1989). Other examples of mineral deficiency that favor pathogen resistance were zinc (Cabot et al., 2019) and iron (Trapet et al., 2021). Readers can find a detailed description of the dual role of the macro-and micronutrients for the infection by bacterial and fungal pathogens elsewhere (Huber et al., 2012).

\section{Continuing Effects of Secondary Messengers, Plant Hormones, and Secondary Metabolites}

The secondary messengers produced during stomatal closure can continue to protect plants. For example, the combination of $\mathrm{ROS} / \mathrm{NO} / \mathrm{Ca}^{2+}$ was quite effective in limiting the spread and multiplication of microbes within the leaf. These secondary messengers trigger hypersensitive response (HR), synthesis of pathogenesis-related (PR) proteins, and programmed cell death (PCD) (Serrano et al., 2015; Marcec et al., 2019). Besides NO, $\mathrm{H}_{2} \mathrm{~S}$ produced during stomatal closure could confer pathogen resistance (Vojtovič et al., 2020). It is possible that these 


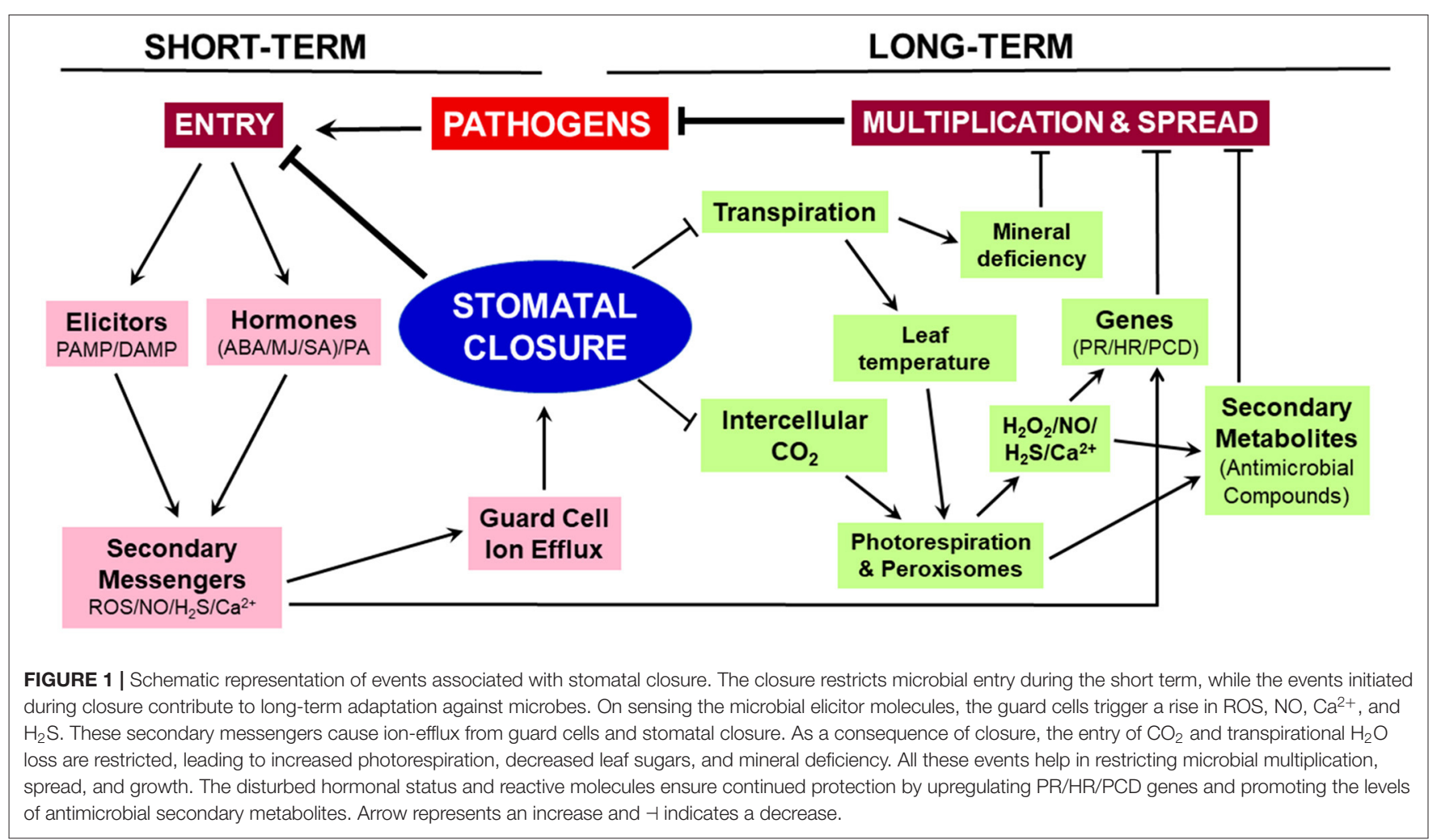

components $\mathrm{ROS} / \mathrm{NO} / \mathrm{Ca}^{2+}$ can also induce priming effect individually or in combination.

When plants were infected by pathogens, the leaves responded by modulating the hormones, which interacted with each other to impart a long-lasting response. Plant hormones (e.g., SA, methyl salicylate, MJ) and even PAs could induce systemic resistance (Bürger and Chory, 2019; Chen et al., 2019; Seifi et al., 2019; Yuan et al., 2019). These hormones (ABA/MJ/SA) primed the plant tissue to stand against pathogens (Agostini et al., 2019; Feng et al., 2020). These observations open up several exciting lines of work for further research.

Several secondary metabolites produced by the plants are prominently associated with protection against bacterial, fungal, and viral attacks. The elevated levels of $\mathrm{H}_{2} \mathrm{O}_{2}, \mathrm{NO}$, and $\mathrm{Ca}^{2+}$ induced accumulation of secondary metabolites like wax, callose, alkaloids, flavonoids, phenols, and PAs, reinforcing the protection against infection (Walters, 2003; Luna et al., 2011; Zaynab et al., 2018; Lewandowska et al., 2020). The PAs also prime the plants against Botrytis (Janse van Rensburg et al., 2021). Similarly, allyl isothiocyanate (AITC) keeps microbes like P. syringae out by inducing stomatal closure (Bednarek, 2012).

\section{CONCLUSION AND FUTURE PERSPECTIVE}

Stomatal closure erects a physical barrier providing immediate relief against the entry of microbial pathogens into leaves while decreasing the rates of photosynthesis and transpiration.
The closure has long-term consequences (Figure 1). The restricted $\mathrm{CO}_{2}$ supply to the mesophyll cells lowers the rate of photosynthesis, stimulates photorespiration and associated $\mathrm{H}_{2} \mathrm{O}_{2}$ production. The elevated levels of $\mathrm{H}_{2} \mathrm{O}_{2}$, along with $\mathrm{NO}, \mathrm{H}_{2} \mathrm{~S}$, and $\mathrm{Ca}^{2+}$, can upregulate genes involved in $\mathrm{HR}, \mathrm{PR}$, and PCD to prevent the spread of pathogens within the leaf. These reactive molecules also promote the accumulation of antimicrobial secondary metabolites. Parallelly, reduced transpiration creates mineral deficiency and limits microbial growth. We suggest that stomatal closure is a trigger to set off long-term events involved in prolonged plant disease resistance.

We know that stomatal closure may not be a universal mechanism to fight the microbial attack, e.g., root or stem pathogens. But several pathogens are air-borne and land on leaves (Melotto et al., 2008; Zeng et al., 2010). Plant-microbe interactions are not unilateral since the pathogens try to reopen stomata using compounds, such as, coronatine (Arnaud and Hwang, 2015). Further work is needed to understand the implications of stomatal closure on the antagonizing responses by the pathogens. Peroxisomal $\mathrm{H}_{2} \mathrm{O}_{2}$ limits microbial growth, but there are instances when microbes use peroxisomes to their advantage (Kubo, 2013). An improved understanding of peroxisomes and manipulation through biotechnological techniques could open up possibilities of designing plants for long-term adaptation to stress conditions. We believe that stomatal guard cells are ideal for studying plants' short-and longterm responses to challenging stress situations. Stomatal closure can be exploited to improve crop growth and grain yield under environmental stress conditions. In crops such as, wheat and 
rice, reduced water requirement due to stomatal closure was used as one of the physiological traits in crop breeding (Park et al., 2020; Paul et al., 2020). Further studies on the longterm effects of stomatal closure can be translated into additional field applications.

\section{AUTHOR CONTRIBUTIONS}

AR conceptualized the idea, prepared the outline, and edited the final version. SG, PB, and AR pooled relevant literature, wrote

\section{REFERENCES}

Agostini, R. B., Postigo, A., Rius, S. P., Rech, G. E., Campos-Bermudez, V. A., and Vargas, W. A. (2019). Long-lasting primed state in maize plants: salicylic acid and steroid signaling pathways as key players in the early activation of immune responses in silks. Mol. Plant Microbe Interact. 32, 95-106. doi: 10.1094/MPMI-07-18-0208-R

Agurla, S., Gahir, S., Munemasa, S., Murata, Y., and Raghavendra, A. S. (2018). Mechanism of stomatal closure in plants exposed to drought and cold stress. Adv. Exp. Med. Biol. 1081, 215-232. doi: 10.1007/978-981-13-1244-1_12

Ahammed, G. J., Li, X., Zhang, G., Zhang, H., Shi, J., Pan, C., et al. (2018). Tomato photorespiratory glycolate-oxidase-derived $\mathrm{H}_{2} \mathrm{O}_{2}$ production contributes to basal defence against Pseudomonas syringae. Plant Cell Environ. 41, 1126-1138. doi: $10.1111 /$ pce. 12932

Arnaud, D., and Hwang, I. (2015). A sophisticated network of signaling pathways regulates stomatal defenses to bacterial pathogens. Mol. Plant 8, 566-581. doi: 10.1016/j.molp.2014.10.012

Bavaresco, L., and Eibach, R. (1987). Investigations on the influence of N fertilizer on resistance to powdery mildew (Oidium tuckeri) downy mildew (Plasmopara viticola) and on phytoalexin synthesis in different grapevine varieties. Vitis 26, 192-200.

Bednarek, P. (2012). Chemical warfare or modulators of defence responses-the function of secondary metabolites in plant immunity. Curr. Opin. Plant Biol. 15, 407-414. doi: 10.1016/j.pbi.2012.03.002

Bezrutczyk, M., Yang, J., Eom, J. S., Prior, M., Sosso, D., Hartwig, T., et al. (2018). Sugar flux and signaling in plant-microbe interactions. Plant J. 93, 675-685. doi: $10.1111 /$ tpj. 13775

Bharath, P., Gahir, S., and Raghavendra, A. S. (2021). Abscisic acid-induced stomatal closure: an important component of plant defense against abiotic and biotic stress. Front. Plant Sci. 12:615114. doi: 10.3389/fpls.2021.615114

Bürger, M., and Chory, J. (2019). Stressed out about hormones: how plants orchestrate immunity. Cell Host Microbe. 26, 163-172. doi: 10.1016/j.chom.2019.07.006

Cabot, C., Martos, S., Llugany, M., Gallego, B., Tolrà, R., and Poschenrieder, C. (2019). A role for zinc in plant defense against pathogens and herbivores. Front. Plant Sci. 10:1171. doi: 10.3389/fpls.2019.01171

Chang, Q., Liu, J., Lin, X., Hu, S., Yang, Y., Li, D., et al. (2017). A unique invertase is important for sugar absorption of an obligate biotrophic pathogen during infection. New Phytol. 215, 1548-1561. doi: 10.1111/nph.14666

Chen, L., Wang, W. S., Wang, T., Meng, X. F., Chen, T. T., Huang, X. X., et al. (2019). Methyl salicylate glucosylation regulates plant defense signaling and systemic acquired resistance. Plant Physiol. 180, 2167-2181. doi: 10.1104/pp.19.00091

Chen, X. L., Wang, Z., and Liu, C. (2016). Roles of peroxisomes in the rice blast fungus. Biomed Res. Int. 2016:9343417. doi: 10.1155/2016/9343417

Cui, H., Tsuda, K., and Parker, J. E. (2015). Effector-triggered immunity: from pathogen perception to robust defense. Ann. Rev. Plant Biol. 66, 487-511. doi: 10.1146/annurev-arplant-050213-040012

Feng, J., Zhang, M., Yang, K. N., and Zheng, C. X. (2020). Salicylic acidprimed defence response in octoploid strawberry "Benihoppe" leaves induces resistance against Podosphaera aphanis through enhanced accumulation of the manuscript, and approved the final manuscript. All authors contributed to the article and approved the submitted version.

\section{FUNDING}

The stomatal work in our laboratory was supported by a grant (to AR) of the Council of Scientific and Industrial Research [No. 38 (1404)/15/EMR-II]. SG was supported by a Senior Research Fellowship from University Grant Commission, New Delhi. PB was supported partially by a University of Hyderabad BBL fellowship.

proanthocyanidins and upregulation of pathogenesis-related genes. BMC Plant Biol. 20:149. doi: 10.1186/s12870-020-02353-z

Fernández-Escobar, R. (2019). Olive nutritional status and tolerance to biotic and abiotic stresses. Front. Plant Sci. 10:1151. doi: 10.3389/fpls.2019.01151

Furutani, R., Makino, A., Suzuki, Y., Wada, S., Shimakawa, G., and Miyake, C. (2020). Intrinsic fluctuations in transpiration induce photorespiration to oxidize P700 in photosystem I. Plants 9:1761. doi: 10.3390/plants9121761

Gahir, S., Bharath, P., and Raghavendra, A. S. (2020). The role of gasotransmitters in movement of stomata: mechanisms of action and importance for plant immunity. Biol. Plant. 64, 623-632. doi: 10.32615/bp.2020.071

Gimenez-Ibanez, S., Chini, A., and Solano, R. (2016). How microbes twist jasmonate signaling around their little fingers. Plants 5:9. doi: 10.3390/plants5010009

Gonugunta, V. K., Srivastava, N., and Raghavendra, A. S. (2009). Cytosolic alkalinization is a common and early messenger preceding the production of ROS and NO during stomatal closure by variable signals, including abscisic acid, methyl jasmonate and chitosan. Plant Signal. Behav. 4, 561-564. doi: $10.4161 /$ psb.4.6.8847

Grimmer, M. K., John Foulkes, M., and Paveley, N. D. (2012). Foliar pathogenesis and plant water relations: a review. J. Exp. Bot. 63, 4321-4331. doi: $10.1093 / \mathrm{jxb} / \mathrm{ers} 143$

Haider, M. S., Kurjogi, M. M., Khalil-Ur-Rehman, M., Fiaz, M., Pervaiz, T., Jiu, S., et al. (2017). Grapevine immune signaling network in response to drought stress as revealed by transcriptomic analysis. Plant Physiol. Biochem. 121, 187-195. doi: 10.1016/j.plaphy.2017.10.026

Hsu, P. K., Dubeaux, G., Takahashi, Y., and Schroeder, J. I. (2021). Signaling mechanisms in abscisic acid-mediated stomatal closure. Plant J. 105, 307-321. doi: $10.1111 /$ tpj.15067

Huai, B., Yang, Q., Wei, X., Pan, Q., Kang, Z., and Liu, J. (2020). TaSTP13 contributes to wheat susceptibility to stripe rust possibly by increasing cytoplasmic hexose concentration. BMC Plant Biol. 20:49. doi: $10.1186 / \mathrm{s} 12870-020-2248-2$

Huber, D., Römheld, V., and Weinmann, M. (2012). "Relationship between nutrition, plant diseases and pests," in Mineral Nutrition of Higher Plants, 3rd Edn, eds P. Marschner (Cambridge, MA: Academic press), 283-298. doi: 10.1016/B978-0-12-384905-2.00010-8

Hugouvieux, V., Barber, C. E., and Daniels, M. J. (1998). Entry of Xanthomonas campestris pv. campestris into hydathodes of Arabidopsis thaliana leaves: a system for studying early infection events in bacterial pathogenesis. Mol. Plant-Microbe Interact. 11, 537-543. doi: 10.1094/MPMI.1998.11.6.537

Janse van Rensburg, H. C., Limami, A. M., and Van den Ende, W. (2021). Spermine and spermidine priming against Botrytis cinerea modulates ROS dynamics and metabolism in Arabidopsis. Biomolecules 11:223. doi: 10.3390/biom11020223

Klüsener, B., Young, J. J., Murata, Y., Allen, G. J., Mori, I. C., Hugouvieux, V., et al. (2002). Convergence of calcium signaling pathways of pathogenic elicitors and abscisic acid in Arabidopsis guard cells. Plant Physiol. 130, 2152-2163. doi: 10.1104/pp.012187

Kohli, S. K., Khanna, K., Bhardwaj, R., Abd Allah, E. F., Ahmad, P., and Corpas, F. J. (2019). Assessment of subcellular ROS and NO metabolism in higher plants: multifunctional signaling molecules. Anti-oxidants 8:641. doi: $10.3390 /$ antiox 8120641 
Kubo, Y. (2013). Function of peroxisomes in plant-pathogen interactions. Subcell. Biochem. 69, 329-345. doi: 10.1007/978-94-007-6889-5_18

Lal, A., Ku, M. S., and Edwards, G. E. (1996). Analysis of inhibition of photosynthesis due to water stress in the $\mathrm{C} 3$ species Hordeum vulgare and Vicia faba: electron transport, $\mathrm{CO}_{2}$ fixation and carboxylation capacity. Photosyn. Res. 49, 57-69. doi: 10.1007/BF00029428

Lewandowska, M., Keyl, A., and Feussner, I. (2020). Wax biosynthesis in response to danger: its regulation upon abiotic and biotic stress. New Phytol. 227, 698-713. doi: 10.1111/nph.16571

Liang, J. S., and Zhang, J. H. (1999). The relations of stomatal closure and reopening to xylem $\mathrm{ABA}$ concentration and leaf water potential during soil drying and rewatering. Plant Growth Regul. 29, 77-86. doi: 10.1023/A:1006207900619

Liu, H., and Xue, S. (2021). Interplay between hydrogen sulfide and other signaling molecules in the regulation of guard cell signaling and abiotic/biotic stress response. Plant Commun. 2:100179. doi: 10.1016/j.xplc.2021.100179

Luna, E., Pastor, V., Robert, J., Flors, V., Mauch-Mani, B., and Ton, J. (2011). Callose deposition: a multifaceted plant defense response. Mol. Plant-Microbe Interact. 24, 183-193. doi: 10.1094/MPMI-07-10-0149

Marcec, M. J., Gilroy, S., Poovaiah, B. W., and Tanaka, K. (2019). Mutual interplay of $\mathrm{Ca}^{2+}$ and ROS signaling in plant immune response. Plant Sci. 283, 343-354. doi: 10.1016/j.plantsci.2019.03.004

Melotto, M., Underwood, W., and He, S. Y. (2008). Role of stomata in plant innate immunity and foliar bacterial diseases. Annu. Rev. Phytopathol. 46, 101-122. doi: 10.1146/annurev.phyto.121107.104959

Melotto, M., Zhang, L., Oblessuc, P. R., and He, S. Y. (2017). Stomatal defense a decade later. Plant Physiol. 174, 561-571. doi: 10.1104/pp.16.01853

Nguyen, Q. M., Iswanto, A., Son, G. H., and Kim, S. H. (2021). Recent advances in effector-triggered immunity in plants: new pieces in the puzzle create a different paradigm. Int. J. Mol. Sci. 22:4709. doi 10.3390/ijms22094709

Park, S. I., Kim, J. J., Shin, S. Y., Kim, Y. S., and Yoon, H. S. (2020). ASR enhances environmental stress tolerance and improves grain yield by modulating stomatal closure in rice. Front. Plant Sci. 10:1752. doi: 10.3389/fpls.2019.01752

Pascual, I., Azcona, I., Morales, F., Aguirreolea, J., and Sánchez-Díaz, M. (2010). Photosynthetic response of pepper plants to wilt induced by Verticillium dahliae and soil water deficit. J. Plant Physiol. 167, 701-708. doi: 10.1016/j.jplph.2009.12.012

Paul, J. M., Watson, A., and Griffiths, C. A. (2020). Linking fundamental science to crop improvement through understanding source and sink traits and their integration for yield enhancement. J. Exp. Bot. 71, 2270-2280. doi: $10.1093 / \mathrm{jxb} / \mathrm{erz} 480$

Richardson, M. D., and Croughan, S. S. (1989). Potassium influence on susceptibility of bermudagrass to Helminthosporium cynodontis toxin. Crop Sci. 29, 1280-1282. doi: 10.2135/cropsci1989.0011183X002900050038x

Ruiz, J. M., and Romero, L. (2002). Renewed debate over transpiration and long-distance transport of minerals in plants. Trends Plant Sci. 7:56. doi: 10.1016/S1360-1385(02)02237-9

Saito, S., and Uozumi, N. (2019). Guard cell membrane anion transport systems and their regulatory components: an elaborate mechanism controlling stressinduced stomatal closure. Plants 8:9. doi: 10.3390/plants8010009

Sawinski, K., Mersmann, S., Robatzek, S., and Böhmer, M. (2013). Guarding the green: pathways to stomatal immunity. Mol. Plant-Microbe Interact. 26, 626-632. doi: 10.1094/MPMI-12-12-0288-CR

Scharte, J., Schön, H., and Weis, E. (2005). Photosynthesis and carbohydrate metabolism in tobacco leaves during an incompatible interaction with Phytophthora nicotianae. Plant Cell Environ. 28, 1421-1435. doi: 10.1111/j.1365-3040.2005.01380.x

Seifi, H. S., Zarei, A., Hsiang, T., and Shelp, B. J. (2019). Spermine is a potent plant defense activator against gray mold disease on Solanum lycopersicum, Phaseolus vulgaris, and Arabidopsis thaliana. Phytopathology 109, 1367-1377. doi: 10.1094/PHYTO-12-18-0470-R

Serrano, I., Romero-Puertas, M. C., Sandalio, L. M., and Olmedilla, A. (2015). The role of reactive oxygen species and nitric oxide in programmed cell death associated with self-incompatibility. J. Exp. Bot. 66, 2869-2876. doi: $10.1093 / \mathrm{jxb} / \mathrm{erv} 083$

Shrestha, R. K., Lei, P., Shi, D., Hashimi, M. H., Wang, S., Xie, D., et al. (2021). Response of maize (Zea mays L.) towards vapor pressure deficit. Environ. Exp. Bot. 181:104293. doi: 10.1016/j.envexpbot.2020.104293
Solomon, P. S., Tan, K. C., and Oliver, R. P. (2003). The nutrient supply of pathogenic fungi; a fertile field for study. Mol. Plant Pathol. 4, 203-210. doi: 10.1046/j.1364-3703.2003.00161.x

Sørhagen, K., Laxa, M., Peterhänsel, C., and Reumann, S. (2013). The emerging role of photorespiration and non-photorespiratory peroxisomal metabolism in pathogen defence. Plant Biol. 15, 723-736. doi: 10.1111/j.1438-8677.2012.00723.x

Sun, L. R., Yue, C. M., and Hao, F. S. (2019). Update on roles of nitric oxide in regulating stomatal closure. Plant Signal. Behav. 14:e1649569. doi: 10.1080/15592324.2019.1649569

Sun, Y., Wang, M., Mur, L., Shen, Q., and Guo, S. (2020). Unravelling the roles of nitrogen nutrition in plant disease defences. Int. J. Mol. Sci. 21:572. doi: $10.3390 /$ ijms 21020572

Taler, D., Galperin, M., Benjamin, I., Cohen, Y., and Kenigsbuch, D. (2004). Plant eR genes that encode photorespiratory enzymes confer resistance against disease. Plant Cell 16, 172-184. doi: 10.1105/tpc.016352

Tanner, W., and Beevers, H. (2001). Transpiration, a prerequisite for long-distance transport of minerals in plants? Proc. Natl. Acad. Sci. U.S.A. 98, 9443-9447. doi: $10.1073 /$ pnas. 161279898

Trapet, P. L., Verbon, E. H., Bosma, R. R., Voordendag, K., Van Pelt, J. A., and Pieterse, C. (2021). Mechanisms underlying iron deficiency-induced resistance against pathogens with different lifestyles. J. Exp. Bot. 72, 2231-2241. doi: $10.1093 / \mathrm{jxb} /$ eraa535

van Butselaar, T., and Van den Ackerveken, G. (2020). Salicylic acid steers the growth-immunity tradeoff. Trends Plant Sci. 25, 566-576. doi: 10.1016/j.tplants.2020.02.002

Vo, K., Rahman, M. M., Rahman, M. M., Trinh, K., Kim, S. T., and Jeon, J. S. (2021). Proteomics and metabolomics studies on the biotic stress responses of rice: an update. Rice 14:30. doi: 10.1186/s12284-021-00461-4

Vojtovič, D., Luhová, L., and Petrivalský, M. (2020). Something smells bad to plant pathogens: production of hydrogen sulfide in plants and its role in plant defence responses. J. Adv. Res. 27, 199-209. doi: 10.1016/j.jare.2020.09.005

Voss, I., Sunil, B., Scheibe, R., and Raghavendra, A. S. (2013). Emerging concept for the role of photorespiration as an important part of abiotic stress response. Plant Biol. 15, 713-722. doi: 10.1111/j.1438-8677.2012.00710.x

Walters, D. (2003). Resistance to plant pathogens: possible roles for free polyamines and polyamine catabolism. New Phytol. 159, 109-115. doi: 10.1046/j.1469-8137.2003.00802.x

Wang, W., Paschalidis, K., Feng, J. C., Song, J., and Liu, J. H. (2019). Polyamine catabolism in plants: a universal process with diverse functions. Front. Plant Sci. 10:561. doi: 10.3389/fpls.2019.00561

Wang, X., Cai, X., Xu, C., Wang, Q., and Dai, S. (2016). Drought-responsive mechanisms in plant leaves revealed by proteomics. Int. J. Mol. Sci. 17:1706. doi: $10.3390 /$ ijms 17101706

Willmer, C. M., and Fricker, M. (1996). Stomata. London: Chapman and Hall. doi: 10.1007/978-94-011-0579-8

Ye, W., Munemasa, S., Shinya, T., Wu, W., Ma, T., Lu, J., et al. (2020). Stomatal immunity against fungal invasion comprises not only chitininduced stomatal closure but also chitosan-induced guard cell death. Proc. Natl. Acad. Sci. U.S.A. 117, 20932-20942. doi: 10.1073/pnas.192231 9117

Yuan, M., Huang, Y., Ge, W., Jia, Z., Song, S., Zhang, L., et al. (2019). Involvement of jasmonic acid, ethylene and salicylic acid signaling pathways behind the systemic resistance induced by Trichoderma longibrachiatum H9 in cucumber. BMC Genom. 20, 1-13. doi: 10.1186/s12864-019-5 513-8

Zaynab, M., Fatima, M., Abbas, S., Sharif, Y., Umair, M., Zafar, M. H., et al. (2018). Role of secondary metabolites in plant defense against pathogens. Microb. Pathog. 124, 198-202. doi: 10.1016/j.micpath.2018.0 8.034

Zeng, W., Melotto, M., and He, S. Y. (2010). Plant stomata: a checkpoint of host immunity and pathogen virulence. Curr. Opin. Biotechnol. 21, 599-603. doi: 10.1016/j.copbio.2010.0 5.006

Conflict of Interest: The authors declare that the research was conducted in the absence of any commercial or financial relationships that could be construed as a potential conflict of interest. 
Publisher's Note: All claims expressed in this article are solely those of the authors and do not necessarily represent those of their affiliated organizations, or those of the publisher, the editors and the reviewers. Any product that may be evaluated in this article, or claim that may be made by its manufacturer, is not guaranteed or endorsed by the publisher.
Copyright $\odot 2021$ Gahir, Bharath and Raghavendra. This is an open-access article distributed under the terms of the Creative Commons Attribution License (CC BY). The use, distribution or reproduction in other forums is permitted, provided the original author(s) and the copyright owner(s) are credited and that the original publication in this journal is cited, in accordance with accepted academic practice. No use, distribution or reproduction is permitted which does not comply with these terms. 